\title{
Power Consumption Model for Macrocell and Microcell Base Stations
}

\author{
Margot Deruyck*, Wout Joseph, Luc Martens \\ Dept. of Information Technology (INTEC), Ghent University/IBBT, Gaston Crommenlaan 8, 9050 Ghent, Belgium \\ \{margot.deruyck,wout.joseph, luc.martens\}@intec.ugent.be
}

\begin{abstract}
In this paper, a power consumption model for both macrocell and microcell base stations is proposed. This model is validated by temporal power measurements on actual base stations and an excellent agreement is obtained. Furthermore, the power consumption's evolution during the day is investigated by means of these measurements. The energy efficiency of three different wireless technologies is compared namely mobile WiMAX, LTE, and HSPA. Based on the model proposed, the deployment tool GRAND (Green Radio Access Network Design) is implemented which allows to design an energyefficient access network for a predefined area.

In general and based on the assumptions made, a macrocell base station consumes about 4.4 times more than a microcell base station. However, a microcell base station is less energy-efficient than a macrocell base station due to its lower coverage range. Despite this, it is still useful to introduce them in the network as the same coverage can be obtained with a lower total power consumption than with a network where only macrocell base stations are used.
\end{abstract}

\section{INTRODUCTION}

An operator's wireless access network has typically a hierarchical structure with different base station types such as the macrocell, the microcell, and the picocell base station. As 9\% of the ICT (Information and Communication Technology) power consumption is caused by radio access networks [1], it is important to determine the power consumption of the whole wireless access network and thus to model the power consumption of each part of this network.

In this study, a power consumption model is proposed for both the macrocell and the microcell base station. Based on this model, the energy efficiency can be compared for various bit rates and for various wireless technologies, such as mobile WiMAX (Worldwide Interoperability for Microwave Access) [2], LTE (Long Term Evolution) [3], and HSPA (High Speed Packet Access) [4]. Furthermore, the evolution of the power consumption during the day is investigated experimentally using temporal power measurements of both an actual macrocell and microcell base station. The predicted power consumption will be compared with these measured values. This power consumption model is then used in the deployment tool GRAND (Green Radio Access Network Design). GRAND allows to design energyefficient wireless access networks (i.e., with minimal power consumption) for a predefined area.
The remainder of this paper is organized as follows. In Section 2, a power consumption model is proposed for both the macrocell and the microcell base station and the temporal behaviour of the power consumption is characterized based on temporal power measurements. Section 3 describes the deployment tool GRAND into details. In Section 4, the power consumption of different wireless technologies (obtained with the model from Section 2) is compared and the influence of the introduction of microcell base stations in the wireless access networks of the technologies considered is investigated (based on the GRAND tool described in Section 3). Section 6 gives the conclusion.

\section{METHOD}

\subsection{Energy efficiency of a base station}

An important parameter to investigate is the energy efficiency of a base station. The energy efficiency is here defined as the power consumption needed to cover a certain area $\left(\right.$ in $\mathrm{W} / \mathrm{m}^{2}$ ). The power consumption $P C_{\text {area }}$ per covered area is then defined as [5]:

$$
P C_{\text {area }}=\frac{P_{e l}}{\pi \cdot R^{2}}
$$

with $P_{e l}$ the power consumption of the base station and $R$ the range of the base station. The lower $P C_{\text {area }}$, the 
more energy-efficient the base station is. Note that the power consumption over the number of information bits is also commonly used in literature [6]. Here, it is assumed that the users are uniformly distributed and all requiring the same bit rate. In this case, this metric is equivalent to $P C_{\text {area }}$. These assumptions are proposed to make a fair comparison between the energy efficiency of the individual macrocell and microcell base stations and between the macrocell network and the hybrid macrocell microcell network.

\subsection{Power consumption of a macrocell base station}

\subsubsection{Theory}

A base station is here defined as the equipment needed to communicate with the mobile stations and with the backhaul network [5]. The area covered by a base station is called a cell which is further divided into a number of sectors. Each sector is covered by a sector antenna, which is a directional antenna with a sector-shaped radiation pattern.

A macrocell base station typically consists of different power consuming components. These components are shown in Fig. 1(a) and can be divided into two groups. The first group is the equipment that is used per sector such as the digital signal processing (responsible for system processing and coding), the power amplifier, the transceiver (responsible for sending and receiving of the signals to the mobile stations), and the rectifier. The power consumption of these components has to be multiplied by the number of sectors $n_{\text {sector }}$ supported by the base station. A macrocell base station has typically three sectors. The second group is the equipment that is common for all sectors, and is thus used once, such as: the microwave link and the air conditioning. The microwave link is used for the communication with the backhaul network and, nowadays, it is often replaced by a fiber link. In this study, the worst-case scenario for a base station is investigated and thus it is assumed that a microwave link is present.

Considering the power consumption of each component, the components can also be divided in the following categories. A first category consists of the components whose power consumption is not load dependent such as the rectifier, the microwave link, and the air conditioning. The load on a base station is determined by the number of users and the services they use in the base station's cell. The higher the number of users and the higher the requirements for the services, the higher the load is. The power consumption of these load-independent components is thus constant throughout time. However, a nuance should be made for the air conditioning. The power consumption of this component depends on the internal and ambient temperature of the base station cabinet (based on information retrieved from data sheets of a manufacturer [7]). An internal and ambient temperature of $25^{\circ} \mathrm{C}$ is assumed which results also in a constant power consumption for the air conditioning. The second category is the equipment that has a load-dependent power consumption (denoted as $\left.P_{e l / l o a d}\right)$ such as the power amplifier, the transceiver, and the digital signal processing. The power consumption of these components should be scaled with a factor $F_{i}$, which is here called the load factor, to determine the power consumption for a specific hour at weekdays or weekends. The power consumption $P_{e l / a m p}$ of the power amplifier also depends on the input power $P_{T x}$ of the antenna and is calculated as follows (in Watt):

$$
P_{e l / a m p}=\frac{P_{T x}}{\eta}
$$

with $\eta$ the efficiency of the power amplifier, which is the ratio of the RF output power to the electrical input power [8].

Once the power consumption of each component is known, the power consumption $P_{e l / m a c r o}$ of the macrocell base station can be determined as follows (in Watt):

$$
P_{e l / \text { macro }}=P_{e l / \text { const }}+P_{\text {el } / \text { load }} \cdot F_{i}
$$

with

$$
\begin{aligned}
P_{\text {el/const }}= & n_{\text {sector }} \cdot P_{\text {el } / \text { rect }}+P_{\text {el/link }}+P_{\text {el/airco }} \\
P_{\text {el/load }}= & n_{\text {sector }} \cdot\left(n_{T x} \cdot\left(P_{\text {el } / \text { amp }}+P_{\text {el } / \text { trans }}\right)\right. \\
& \left.+P_{\text {el } / \text { proc }}\right)
\end{aligned}
$$

$n_{\text {sector }}$ is the number of sectors supported by the macrocell base station, $F_{i}\left(i=0 . .23,0 \leq F_{i} \leq 1\right)$ the load factor, $n_{T x}$ the number of transmitting antennas and $P_{\text {el/rect }}, P_{\text {el/link }}, P_{\text {el/airco }}, P_{\text {el/amp }}, P_{\text {el/trans }}$ and $P_{e l / p r o c}$ the power consumption of, respectively, the rectifier, the microwave link (if present), the air conditioning, the power amplifier, the transceiver, and the digital signal processing (in Watt).

Table I summarizes the typical power consumption of the different components for the technologies considered. These values are retrieved from data sheets of various network equipment manufacturers and private interviews with the operator $[9,10,11,12,13,14]$.

\begin{tabular}{|l|c|c|c|}
\hline Equipment & & $\begin{array}{c}\text { Macrocell } \\
\text { base station }\end{array}$ & $\begin{array}{c}\text { Microcell } \\
\text { base station }\end{array}$ \\
\hline Number of sectors & $n_{\text {sector }}$ & 3 & 1 \\
\hline $\begin{array}{l}\text { Number of transmitting } \\
\text { antennas per sector }\end{array}$ & $n_{T x}$ & 1 & 1 \\
\hline Digital signal processing & $P_{\text {el/proc }}$ & $100 \mathrm{~W}$ & $100 \mathrm{~W}$ \\
\hline Power amplifier & $\eta$ & $12.8 \%$ & $12 \%$ \\
\hline Transceiver & $P_{e l / \text { trans }}$ & $100 \mathrm{~W}$ & $100 \mathrm{~W}$ \\
\hline Rectifier & $P_{\text {el/rect }}$ & $100 \mathrm{~W}$ & $100 \mathrm{~W}$ \\
\hline Air conditioning & $P_{\text {el/airco }}$ & $225 \mathrm{~W}$ & $60 \mathrm{~W}$ \\
\hline Microwave link & $P_{\text {el/link }}$ & $80 \mathrm{~W}$ & - \\
\hline
\end{tabular}

Table I. Power consumption of the macrocell and microcell base station components for the technologies considered (mobile WiMAX, HSPA and LTE). 


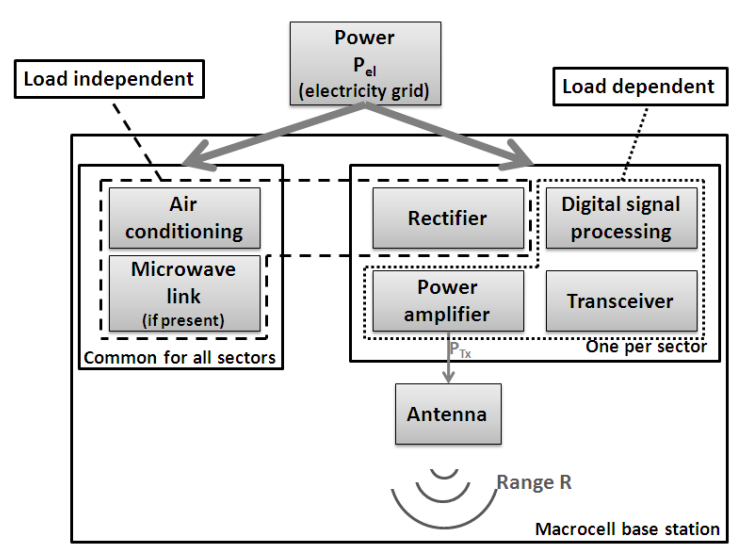

(a)

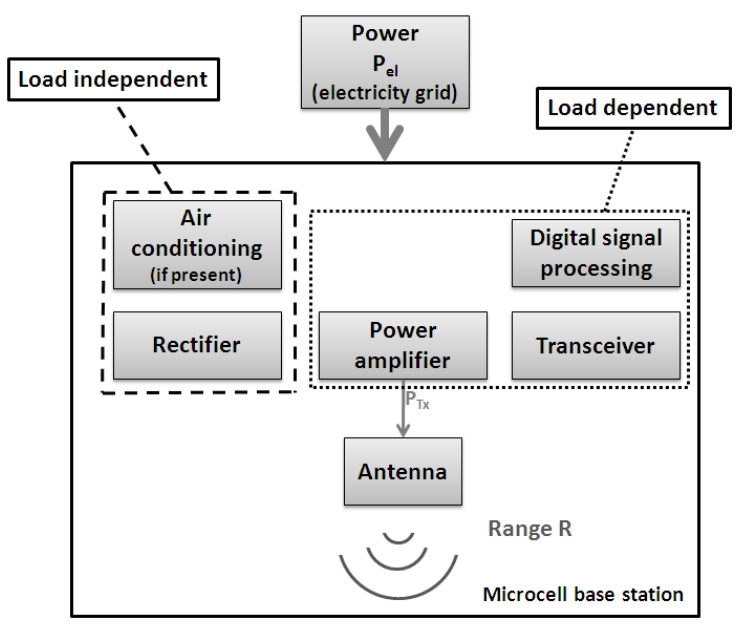

(b)

Figure 1. Block diagram of the macrocell (a) and the microcell (b) base station.

\subsubsection{Measurements}

To determine the load factor $F_{i}$, measurements are performed for an actual HSPA macrocell base station in the suburban area of Ghent, Belgium. During six days (5 weekdays and 1 weekend day), the power consumption of the base station is measured. The group of load-independent components i.e., the rectifier, the air conditioning and the microwave link, was not included in these measurements. For the equipment considered, the voltage is constant (i.e., approximately $54 \mathrm{~V}$ ) and thus only the current was measured. The power consumption $P(t)$ at a certain time $t$ is then determined as follows (in Watt):

$$
P(t)=V \cdot I(t)
$$

with $V$ the voltage (in volt) and $I$ the current at time $t$ (in ampere).

The current was measured with an AC/DC current clamp (Fluke i410). Every second, the value of the current was saved which results in 466,319 samples for the measurement period of six days. Fig. 2 shows the power consumption (in Watt) as a function of the time. In Fig. 2, day 1 till 5 are weekdays and day 6 is a weekend day. For the week days, it is noticed that the power consumption at night (i.e., from midnight till 8 a.m.) is lower than during the day (i.e., from 8 a.m. till midnight) because during the day more people are active than at night. Also during weekdays, more people are coming to town, for example, to work. For the weekend day, this difference in power consumption is smaller than for weekdays.

Based on the data shown in Fig. 2, the average power consumption per hour for weekdays and for the weekend is calculated. These averages are presented in Table II. The measured equipment consumes between $1016 \mathrm{~W}$ and $1087 \mathrm{~W}$.
Determining the power consumption with our model (eq. (3), $F_{i}=1, P_{T x}=43 \mathrm{dBm}$, including load independent equipment) and the data from Table I results in a power consumption of $1673 \mathrm{~W}$. Excluding the power consumption of the rectifiers, the microwave link and the air conditioning results in a power consumption of $1068 \mathrm{~W}$ which agrees very well (standard deviation of $2.0 \%$ ) with the range of power consumptions in Table II. The load factor $F_{10}$ for the time between $10 \mathrm{a} . \mathrm{m}$. and $11 \mathrm{a} . \mathrm{m}$. on a weekday is chosen to be 1 as this time interval corresponds with the highest power consumption (which corresponds with an average of 165 voice calls and 766 data calls during this hour). The minimum, maximum, and average number of voice and data calls for different time periods are shown in Table III. As expected the highest number of voice and data calls is found during weekdays and at daytime. The load factor $F_{i}(i=0 . .23)$ for each hour of a weekday can then be determined. These load factors can be found in Table II. One might argue that $F_{i}$ represents the impact of the time on the power consumption of the base station rather than the impact of the load. However, a different point in time will result in a different load as shown in [15] and thus reflects $F_{i}$ implicitly the impact of the load. Furthermore, it is also important that the $F_{i}$ model is representative for other macrocell base stations in the suburban city environment as well. For other environments such as residential areas, rural terrain, industrial environment, etc., a new model for $F_{i}$ should be determined following the above described procedure. This is a similar approach as in [15] where for each environment one site is selected to perform measurements. Here, the suburban city environment is chosen as this is the most interesting case to investigate.

For the weekend, the fluctuations in power consumption are small as shown in Table II because the difference 


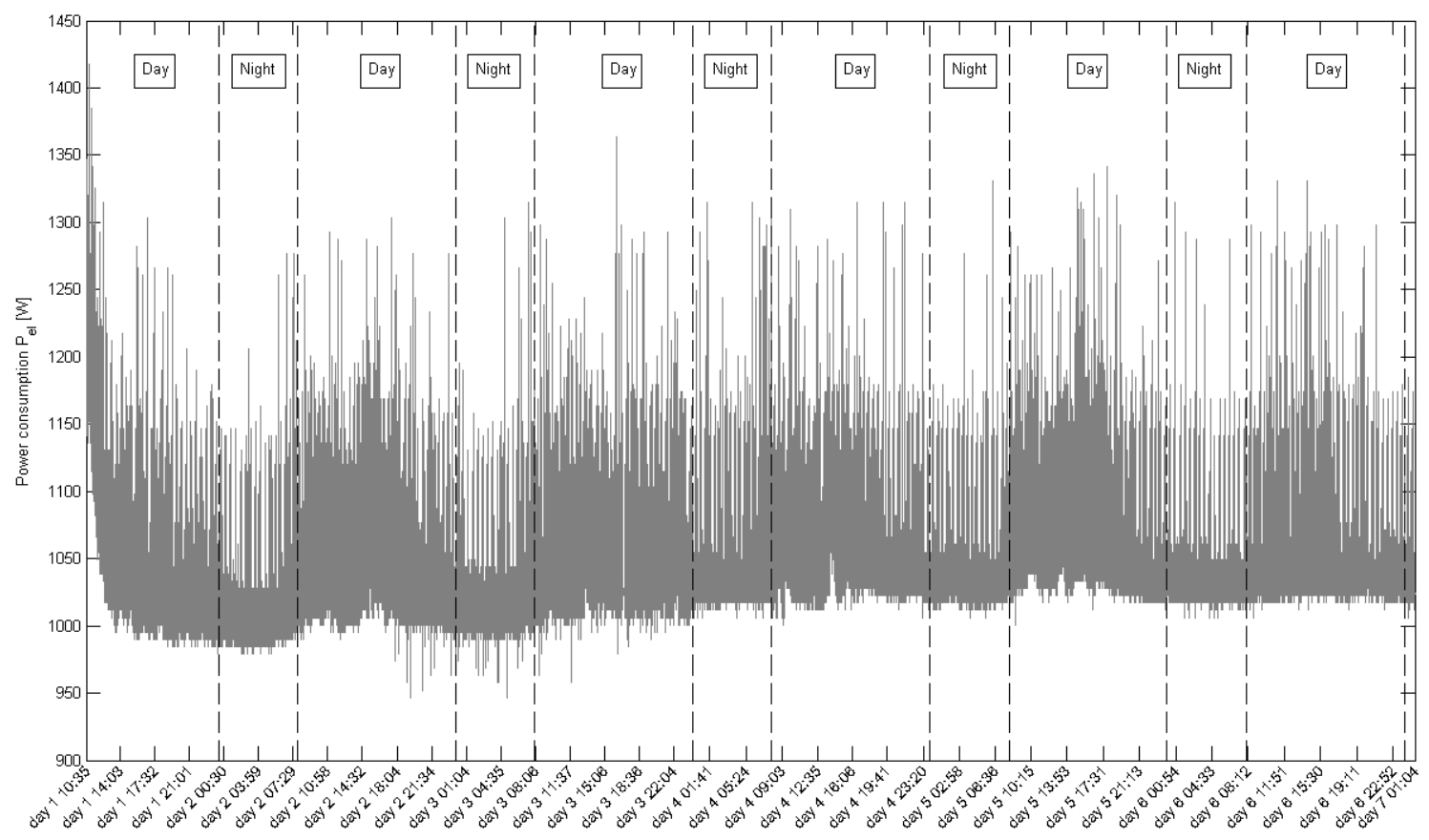

Figure 2. Evolution of the power consumption in time (Days 1-5 weekdays, day 6 weekend day).

\begin{tabular}{|c|c|c|c|c|c|c|}
\hline & \multicolumn{3}{|c|}{ Macrocell base station } & \multicolumn{3}{|c|}{ Microcell base station } \\
\hline Hour & Weekday & Weekend & $\begin{array}{c}\text { Factor } \\
\text { Week }\end{array}$ & Weekday & Weekend & $\begin{array}{c}\text { Factor } \\
\text { Week }\end{array}$ \\
\hline 0 a.m. - 1 a.m. & $1018 \mathrm{~W}$ & $1029 \mathrm{~W}$ & $F_{0}=0.94$ & $220 \mathrm{~W}$ & $227 \mathrm{~W}$ & $F_{0}=0.96$ \\
\hline 1 a.m. - 2 a.m. & $1017 \mathrm{~W}$ & $1028 \mathrm{~W}$ & $F_{1}=0.94$ & $214 \mathrm{~W}$ & $224 \mathrm{~W}$ & $F_{1}=0.93$ \\
\hline 2 a.m. - 3 a.m. & $1017 \mathrm{~W}$ & $1027 \mathrm{~W}$ & $F_{2}=0.94$ & $221 \mathrm{~W}$ & $220 \mathrm{~W}$ & $F_{2}=0.97$ \\
\hline 3 a.m. - 4 a.m. & $1016 \mathrm{~W}$ & $1026 \mathrm{~W}$ & $F_{3}=0.93$ & $220 \mathrm{~W}$ & $221 \mathrm{~W}$ & $F_{3}=0.96$ \\
\hline 4 a.m. -5 a.m. & $1016 \mathrm{~W}$ & $1024 \mathrm{~W}$ & $F_{4}=0.93$ & $221 \mathrm{~W}$ & $227 \mathrm{~W}$ & $F_{4}=0.97$ \\
\hline 5 a.m. -6 a.m. & $1017 \mathrm{~W}$ & $1024 \mathrm{~W}$ & $F_{5}=0.94$ & $217 \mathrm{~W}$ & $226 \mathrm{~W}$ & $F_{5}=0.95$ \\
\hline 6 a.m. - 7 a.m. & $1020 \mathrm{~W}$ & $1025 \mathrm{~W}$ & $F_{6}=0.94$ & $224 \mathrm{~W}$ & $218 \mathrm{~W}$ & $F_{6}=0.98$ \\
\hline 7 a.m. -8 a.m. & $1026 \mathrm{~W}$ & $1025 \mathrm{~W}$ & $F_{7}=0.94$ & $221 \mathrm{~W}$ & $224 \mathrm{~W}$ & $F_{7}=0.97$ \\
\hline 8 a.m. - 9 a.m. & $1044 \mathrm{~W}$ & $1027 \mathrm{~W}$ & $F_{8}=0.96$ & $229 \mathrm{~W}$ & $232 \mathrm{~W}$ & $F_{8}=1.00$ \\
\hline 9 a.m. - 10 a.m. & $1057 \mathrm{~W}$ & $1032 \mathrm{~W}$ & $F_{9}=0.97$ & $219 \mathrm{~W}$ & $223 \mathrm{~W}$ & $F_{9}=0.96$ \\
\hline 10 a.m. - 11 a.m. & $1087 \mathrm{~W}$ & $1031 \mathrm{~W}$ & $F_{10}=1.00$ & $225 \mathrm{~W}$ & $225 \mathrm{~W}$ & $F_{10}=0.98$ \\
\hline 11 a.m. - 12 p.m. & $1073 \mathrm{~W}$ & $1033 \mathrm{~W}$ & $F_{11}=0.99$ & $222 \mathrm{~W}$ & $229 \mathrm{~W}$ & $F_{11}=0.97$ \\
\hline 12 p.m. - 1 p.m. & $1055 \mathrm{~W}$ & $1036 \mathrm{~W}$ & $F_{12}=0.97$ & $219 \mathrm{~W}$ & $229 \mathrm{~W}$ & $F_{12}=0.96$ \\
\hline 1 p.m. - 2 p.m. & $1060 \mathrm{~W}$ & $1035 \mathrm{~W}$ & $F_{13}=0.98$ & $226 \mathrm{~W}$ & $223 \mathrm{~W}$ & $F_{13}=0.99$ \\
\hline 2 p.m. - 3 p.m. & $1070 \mathrm{~W}$ & $1037 \mathrm{~W}$ & $F_{14}=0.98$ & $219 \mathrm{~W}$ & $222 \mathrm{~W}$ & $F_{14}=0.96$ \\
\hline 3 p.m. - 4 p.m. & $1065 \mathrm{~W}$ & $1035 \mathrm{~W}$ & $F_{15}=0.98$ & $221 \mathrm{~W}$ & $224 \mathrm{~W}$ & $F_{15}=0.97$ \\
\hline 4 p.m. - 5 p.m. & $1049 \mathrm{~W}$ & $1038 \mathrm{~W}$ & $F_{16}=0.97$ & $220 \mathrm{~W}$ & $227 \mathrm{~W}$ & $F_{16}=0.96$ \\
\hline 5 p.m. - 6 p.m. & $1044 \mathrm{~W}$ & $1036 \mathrm{~W}$ & $F_{17}=0.96$ & $221 \mathrm{~W}$ & $226 \mathrm{~W}$ & $F_{17}=0.97$ \\
\hline 6 p.m. - 7 p.m. & $1042 \mathrm{~W}$ & $1034 \mathrm{~W}$ & $F_{18}=0.96$ & $222 \mathrm{~W}$ & $223 \mathrm{~W}$ & $F_{18}=0.97$ \\
\hline 7 p.m. - 8 p.m. & $1034 \mathrm{~W}$ & $1039 \mathrm{~W}$ & $F_{19}=0.95$ & $220 \mathrm{~W}$ & $221 \mathrm{~W}$ & $F_{19}=0.96$ \\
\hline 8 p.m. - 9 p.m. & $1034 \mathrm{~W}$ & $1033 \mathrm{~W}$ & $F_{20}=0.95$ & $219 \mathrm{~W}$ & $225 \mathrm{~W}$ & $F_{20}=0.96$ \\
\hline 9 p.m. - 10 p.m. & $1033 \mathrm{~W}$ & $1033 \mathrm{~W}$ & $F_{21}=0.95$ & $221 \mathrm{~W}$ & $228 \mathrm{~W}$ & $F_{21}=0.97$ \\
\hline 10 p.m. - 11 p.m. & $1033 \mathrm{~W}$ & $1030 \mathrm{~W}$ & $F_{22}=0.95$ & $219 \mathrm{~W}$ & $228 \mathrm{~W}$ & $F_{22}=0.96$ \\
\hline 11 p.m. - 0 a.m. & $1024 \mathrm{~W}$ & $1030 \mathrm{~W}$ & $F_{23}=0.94$ & $221 \mathrm{~W}$ & $223 \mathrm{~W}$ & $F_{23}=0.97$ \\
\hline
\end{tabular}

Table II. Average power consumption per hour during weekdays and weekends for a macrocell and a microcell base station (only load dependent equipment). 


\begin{tabular}{|l|c|c|c|c|c|c|c|c|c|}
\hline & \multicolumn{4}{|c|}{ Macrocell BS } & \multicolumn{3}{c|}{ Microcell BS } \\
\hline & \multicolumn{2}{|c|}{ Minimum } & \multicolumn{2}{c|}{ Maximum } & \multicolumn{2}{c|}{ Average } & Minimum & Maximum & Average \\
\hline & No. voice & No. data & No. voice & No. data & No. voice & No. data & Erlang & Erlang & Erlang \\
\hline Weekday & 0 & 1163 & 227 & 28 & 86 & 375 & 0 & 3.093 & 0.861 \\
\hline Weekend day & 0 & 44 & 79 & 207 & 23 & 113 & 0 & 1.088 & 0.328 \\
\hline Daytime & 7 & 28 & 227 & 311 & 105 & 109 & 0.015 & 3.093 & 0.834 \\
\hline Night & 0 & 44 & 59 & 1163 & 7 & 422 & 0 & 1.078 & 0.092 \\
\hline
\end{tabular}

Table III. Overview of maximum, minimum, and average number of voice and data calls, resp. Erlang, for a macrocell BS, resp. microcell BS for different periods in time.

between the number of active users at night and during the day is smaller than for weekdays. For example, during the weekend offices are closed and less people are coming to town. Therefore, only one average load factor $F$ is determined for the weekend. The average power consumption for the weekend is $1031 \mathrm{~W}$ per hour (excluding load independent equipment, average of 22 voice and 113 data calls during the weekend) which corresponds with $F$ equalling 0.95 . Table III shows that there are less users active during a weekend day which results thus in a lower $F$.

Note that the off-peak load for a base station is very low compared to the peak value (Table III), while this can not be seen in the evolution of the power consumption (Fig. 2) due to the fact that variations in traffic are not always followed by similar variations in energy consumption as already concluded by $[16,17]$.

\subsection{Power consumption of a microcell base station}

\subsubsection{Theory}

Analogously as for the macrocell base station, a microcell base station consists of several power-consuming components which are shown in Fig. 1(b). The following components are present: the transceiver, the digital signal processing, the power amplifier, the rectifier, and the air conditioning. However, the air conditioning is not always required. In this paper, the worst-case scenario is investigated as mentioned before and, therefore, the air conditioning is included. In contrast to a macrocell base station, a microcell base station supports only one sector (omnidirectional antenna) and each component is thus used once. These assumptions are made based on the confidential information retrieved from an operator.

The power consumption $P_{e l / m i c r o}$ of a microcell base station is then determined as follows (in Watt):

$$
P_{e l / m i c r o}=P_{e l / \text { const }}+P_{e l / l o a d} \cdot F_{i}
$$

with

$$
\begin{aligned}
P_{\text {el/const }} & =P_{\text {el } / \text { rect }}+P_{\text {el/airco }} \\
P_{\text {el } / \text { load }} & =P_{\text {el } / \text { amp }}+P_{\text {el } / \text { trans }}+P_{\text {el } / \text { proc }}
\end{aligned}
$$

with $F_{i}\left(i=0 . .23,0 \leq F_{i} \leq 1\right)$ the load factor and $P_{\text {el/rect }}, P_{\text {el/airco }}, P_{\text {el/amp }}, P_{\text {el/trans }}$, and $P_{\text {el/proc }}$ the power consumption of, respectively, the rectifier, the air conditioning, the power amplifier, the transceiver and the digital signal processing (in Watt). $P_{e l / a m p}$ is again determined with eq. (2). Table I summarizes the typical power consumption of the different components. These values are similar to those of the macrocell base station, except for the air conditioning. The cooling power of the air conditioning is significantly lower for a microcell base station, resulting in a lower power consumption (based on private interviews with the operator). The load factor $F_{i}$ is again determined based on measurements described in the next section.

\subsubsection{Measurements}

As mentioned before, the load factor $F_{i}$ for the microcell base station is also determined based on measurements in a suburban environment. The same measurement procedure as for the macrocell base station is used (Section 2.2.2). However, for the microcell base station, the voltage amounts to $48 \mathrm{~V}$ instead of $54 \mathrm{~V}$ as for the macrocell base station. During these measurements, 469,919 samples were obtained. Fig. 3 illustrates the power consumption (in Watt) as a function of time. Although the power consumption fluctuates again over time, the difference in power consumption during day and night, as noticied by the macrocell base station, is not present for the microcell base station.

Based on the data shown in Fig. 3, the average power consumption per hour for weekdays and for the weekend is calculated. These averages are presented in Table II. The measured equipment consumes between $214 \mathrm{~W}$ and $232 \mathrm{~W}$.

Determining the power consumption with our model (eq. (5), $F_{i}=1, P_{T x}=33 \mathrm{dBm}$, including load independent equipment) and the data from Table I results in a power consumption of $377 \mathrm{~W}$. Excluding the power consumption of the rectifiers, the microwave link and the air conditioning results in a power consumption of $217 \mathrm{~W}$ which agrees again excellent (a standard deviation of $1.4 \%$ ) with the range of power consumptions in Table II. The power consumption obtained with our model corresponds with the average power consumption for weekdays during the following hours: between 5 a.m. and 6 a.m., 9 a.m. and 10 a.m., 12 p.m. and 1 p.m., 2 p.m. and 3 p.m., 8 p.m. and 9 p.m., and 10 p.m. and 11 p.m. 


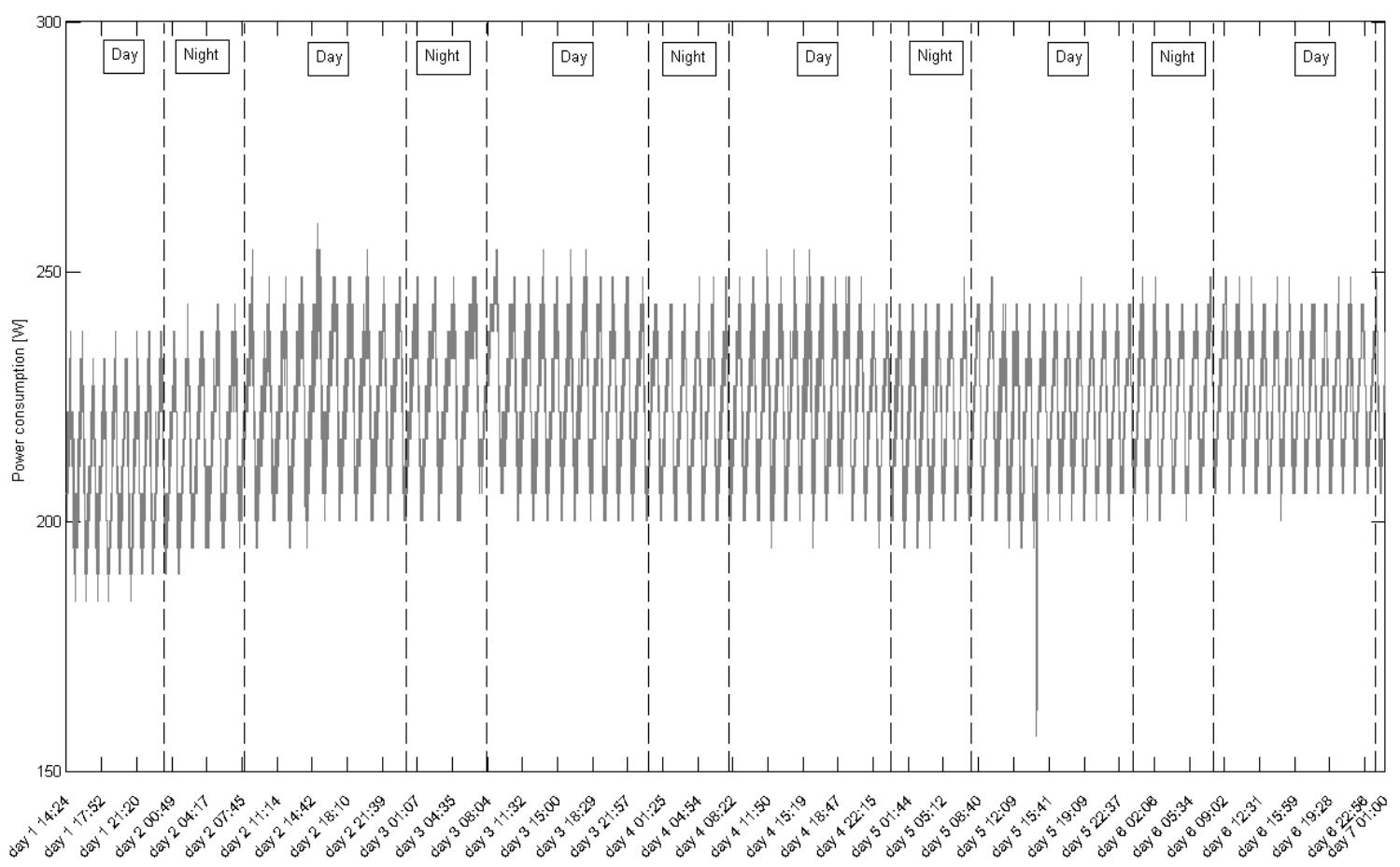

Figure 3. Evolution of the power consumption in time (Day 1-5 weekdays, day 6 weekend day).

This also validates our model. The load factor $F_{8}$ for the time between 8 a.m. and 9 a.m. is set to be 1 as this is the time interval with the highest power consumption (average of 0.44 Erlang). Table III shows the minimum, maximum, and average Erlang for different time periods. The same tendency as for the macrocell base station i.e., during the week and during daytime more users are active, can be noticed. The other load factors can be found in Table II.

For the weekend, the fluctuations in power consumption are small as shown in Table II. Therefore, again only one average load factor $F$ is determined for these hours. The average power consumption for the weekend is $225 \mathrm{~W}$ which corresponds with $F$ equals to 0.98 (average of 0.33 Erlang).

\subsection{Range of a base station}

\subsubsection{Link budget}

To determine the coverage of a base station, a link budget has to be calculated. A link budget takes into account all of the gains and the losses from the transmitter through the medium to the receiver. For this determination, the maximum allowable path loss $P L_{\max }$ to which a transmitted signal can be subjected while still being high enough at the receiver has to be calculated. It includes all the possible elements of loss associated with interactions between the transmit and the receive antennas and is defined as the ratio of the transmitted power to the received power of the signal [18]. Table IV summarizes the link budget parameters for the coverage calculations of both the macrocell and microcell base station for all technologies considered.

Some parameters of Table IV have the same value for both the macrocell and the microcell base station because these parameters are either technology dependent (such as the frequency, bandwidth, etc.), or mobile station dependent (such as the antenna gain and the feeder loss of the mobile station), or based on environmental assumptions (such as the fade margin). The values for the input power $P_{T x}$ of the antenna and the antenna gain of the base station differ between a macrocell and a microcell base station. A microcell base station has a typical $P_{T x}$ of $2 \mathrm{~W}$, also $6 \mathrm{~W}$ is possible. In this study, a $P_{T x}$ of $2 \mathrm{~W}$ is used which corresponds with $33 \mathrm{dBm}$ [19]. As mentioned above, a microcell base station supports only one sector, therefore, an omnidirectional antenna is used. The antenna gain for this type of antennas varies from 4 to $6 \mathrm{~dB}$ depending on the technology.

\subsubsection{Transmission modes}

In mobile telecommunication systems, the mobile stations typically support different transmission modes. These transmission modes are determined by a coding rate and a modulation scheme. For wireless communication, the binary bit stream has first to be translated into an analogue signal which can be done by using a modulation scheme such as QPSK (Quadrature Phase Shifting Keying) and 16- or 64-QAM (Quadrature Amplitude Modulation). Furtermore, a coding rate is used for FEC (Forward Error Correction) which is responsible for the correction 


\begin{tabular}{|c|c|c|c|c|c|c|}
\hline Parameter & & crocell base sta & & & crocell base sta & \\
\hline & $\begin{array}{l}\text { Mobile } \\
\text { WiMAX }\end{array}$ & HSPA & LTE & $\begin{array}{l}\text { Mobile } \\
\text { WiMAX }\end{array}$ & HSPA & LTE \\
\hline Frequency [MHz] & 2500 & 2100 & 2600 & 2500 & 2100 & 2600 \\
\hline $\begin{array}{l}\text { Maximum input power } \\
\text { of base station } P_{T x}[\mathrm{dBm}]\end{array}$ & 35 & 43 & 43 & 33 & 33 & 33 \\
\hline $\begin{array}{l}\text { Effective input power } \\
\text { of base station } P_{T x}^{T C H}[\mathrm{dBm}]\end{array}$ & 35 & 24.7 & 43 & 33 & 13.8 & 33 \\
\hline Antenna gain of base station $[\mathrm{dBi}]$ & 16 & 17.4 & 18 & 6 & 5 & 4 \\
\hline Antenna gain of mobile station [dBi] & 2 & 0 & 0 & 2 & 0 & 0 \\
\hline Soft handover gain $[\mathrm{dB}]$ & 0 & 1.5 & 0 & 0 & 1.5 & 0 \\
\hline Feeder loss of base station $[\mathrm{dB}]$ & 0.5 & 0 & 2 & 0.5 & 0 & 2 \\
\hline Feeder loss of mobile station $[\mathrm{dB}]$ & 0 & 0 & 0 & 0 & 0 & 0 \\
\hline Fade margin $[\mathrm{dB}]$ & 10 & 10 & 10 & 10 & 10 & 10 \\
\hline Interference margin $[\mathrm{dB}]$ & 2 & 2 & 2 & 2 & 2 & 2 \\
\hline Bandwidth [MHz] & 5 & 5 & 5 & 5 & 5 & 5 \\
\hline Receiver SNR [dB] & $\begin{array}{l}{[6,8.5,11.5} \\
15,19,21]^{1}\end{array}$ & $\begin{array}{c}{[-3.1,0.1,3.4} \\
6,7.1,9.6 \\
15.6]^{2}\end{array}$ & $\begin{array}{c}{[-1.5,3,10.5} \\
14,19,23 \\
23,29.4]^{3}\end{array}$ & $\begin{array}{l}{[6,8.5,11.5} \\
15,19,21]^{1}\end{array}$ & $\begin{array}{c}{[-3.1,0.1,3.4} \\
6,7.1,9.6 \\
15.6]^{2}\end{array}$ & $\begin{array}{c}-1.5,3,10.5 \\
14,19,23 \\
23,29.4]^{3}\end{array}$ \\
\hline Number of used subcarriers & 360 & - & 301 & 360 & - & 301 \\
\hline Number of total subcarriers & 512 & - & 512 & 512 & - & 512 \\
\hline Noise figure of mobile station $[\mathrm{dB}]$ & 7 & 9 & 8 & 7 & 9 & 8 \\
\hline $\begin{array}{l}\text { Implementation loss } \\
\text { of mobile station }[\mathrm{dB}]\end{array}$ & 2 & 0 & 0 & 2 & 0 & 0 \\
\hline
\end{tabular}

(1) [1/2 QPSK, 3/4 QPSK, 1/2 16-QAM, 3/4 16-QAM, 2/3 64-QAM, 3/4 64-QM]

(2) [1/4 QPSK, 1/2 QPSK, 3/4 QPSK, 3/4 8-QAM, 1/2 16-QAM, 3/4 16-QAM, 3/4 64-QAM]

(3) [1/3 QPSK, 1/2 QPSK, 2/3 QPSK, 1/2 16-QAM, 2/3 16-QAM, 4/5 16-QAM, 1/2 64-QAM, 2/3 64-QAM]

Table IV. Link budget table for a macrocell and microcell base station for the technologies considered.

of errors occurred. The coding rate indicates how many redundant bits will be added per number of information bits. The modulation scheme and the coding rate have an important role in the determination of the physical bit rate. Each transmission mode is characterized by a receiver SNR (Signal-to-Noise Ratio) which represents the required SNR at the receiver for a certain Bit Error Error (BER) (here, a BER of $10^{-6}$ is assumed). It is thus a determining factor for the required signal power which indicates what the signal power level is for just acceptable communication quality. Table IV gives an overview of the different transmission modes supported by each technology and the corresponding receiver SNR. The higher the modulation scheme and coding rate, the higher the required receiver SNR, the higher the bit rate and the lower the range which results in a lower energy efficiency as illustrated in $[5,20]$.

\subsubsection{Interference}

To take the interference into account, a special margin, the interference margin, is introduced in the link budget (Table IV). This margin represents the interference a user might experience due to other users in the same cell, as well as the interference caused by neighbouring cells. Increasing coverage is the main objective in the comparison, and thus the same interference margin (i.e., $2 \mathrm{~dB}$ ) is assumed for both the macrocell and the microcell base station as done in [19]. When the purpose is to increase throughput, the microcell base station will be mainly located within the cell covered by the macrocell base station (the so-called umbrella structure) and a more exhaustive study of the inference will be needed [21].

\subsubsection{Scenario}

Once $P L_{\max }$ is known, the range can be determined by using a propagation model. For the macrocell base station, the Erceg C model is used [22], while for the microcell base station the Walfisch-Ikegami (WI) model is more suitable [23]. The characteristics of the scenario considered are listed in Table V. A suburban area is assumed with a height of $1.5 \mathrm{~m}$ for the mobile stations. For the macrocell base stations, a height of $30 \mathrm{~m}$ is assumed, while for the microcell base station a height of $6 \mathrm{~m}$ is chosen which corresponds with the height of the roofgutter of a two-storied house (i.e., $3 \mathrm{~m}$ per floor). Both the base stations are placed outdoor. Furthermore, for the mobile stations, an indoor residential scenario is assumed. The mobile stations considered are laptops equipped with a WNIC (Wireless Network Interface Card). 


\begin{tabular}{|l|c|c|}
\hline Parameter & Macrocell base station & Microcell base station \\
\hline Area type & Suburban & Suburban \\
\hline Height of the base station $h_{B S}[\mathrm{~m}]$ & 30 & 6 \\
\hline Height of the mobile station $h_{M S}[\mathrm{~m}]$ & 1.5 & 1.5 \\
\hline Coverage requirement & $90 \%$ & $90 \%$ \\
\hline Propagation model & Erceg C & W-I \\
\hline Shadowing margin $[\mathrm{dB}]$ & 13.2 & 12.8 \\
\hline Building penetration loss $[\mathrm{dB}]$ & 8.1 & 8.1 \\
\hline
\end{tabular}

Table V. Suburban scenario under consideration.

\section{OPTIMIZATION TOOL FOR GREEN WIRELESS ACCESS NETWORKS}

The model described in Section 2 is used in the deployment tool GRAND (Green Radio Access Network Design) for design and optimization of green wireless access networks. The purpose of the tool is to cover a specific area, the target area, as energy-efficiently (i.e., with minimal power consumption) as possible. This tool is based on the work presented in [5]. The tool can optimize existing networks of operators or it can support the deployment of a new network. The investigation of the latter is the focus of this study. In [5], optimization of existing networks is discussed.

The algorithm for determination of the energy-efficient network is based on a genetic search algorithm. A flow chart of our algorithm can be found in Fig. 4.

Firstly, the target area is loaded in shapefile format (Block 1 in Fig. 4). A shapefile stores non-topological geometry and attribute information for the spatial features in the data set [24]. The geometry of a feature is stored as a shape comprising a set of vector coordinates. The shapefile contains, amongst others, information about the position, the form, and the height of the buildings in the target area. An example can be found in Fig. 5(a) showing a 3D shapefile of Ghent, Belgium. Based on this information, a set of possible locations for the base station positions is determined (Block 2 in Fig. 4). A base station can be placed on each building with a height equal to or higher than the height chosen by the user. This threshold can be chosen freely, however, the lower this threshold, the larger the set of possible base station locations and thus the longer the calculation time. The antenna of both the macrocell and the microcell base station will be placed at the height of the building.

Secondly, a first set or population of solutions is generated by using mutations (Block 3 in Fig. 4). Each solution of this population is a possible network to cover the target area. The size of the population is defined by the user self. Initially all base stations are inactive. Through various mutations different solutions are created. Six different mutations are defined in the GRAND tool:

- Make an inactive base station active or an active base station inactive.
- Add $1 \mathrm{dBm}$ to or remove $1 \mathrm{dBm}$ from the input power of the antenna of an active base station (maximum value equals one of those in Table IV, the minimum value is $0 \mathrm{dBm}$ ).

- Change the cell type of the base station (a macrocell base station becomes a microcell base station and vice versa).

Which base station and how it will be adapted, is determined at random. The mutations are also used in step 4 (Fig. 4) of the algorithm.

Next, this initial population will be improved through generations (Block 4 in Fig. 4). A new generation population is created by mutating solutions of the previous generation, by selecting the best solutions in the previous generation (based on a fitness function (Block 5 in Fig. 4)), and by the crossover operator until the chosen population size is reached again. The new population is then used in the next iteration of the algorithm until the stop condition is met (Block 7 in Fig. 4). More information about the selection procedure, the fitness function, the crossover operator, and the stop condition can be found in [5]. Note that the model described in Section 2 is used for determining the solution fitness, which measures the quality of the solution (Block 6 in Fig. 4) in terms of coverage and power consumption.

Once the stop condition is met, the algorithm enters its last stage (Block 8 in Fig. 4). It was chosen to use a heuristic i.e., a genetic search algorithm, as it is very hard and timeconsuming to solve the problem in a deterministic way. Due to the heuristic nature of the algorithm, it is possible that, some base stations cover a piece of the target area that is already covered by other base stations. The purpose of the last step of the algorithm is to remove this kind of overlap.

The final result of the tool is a shapefile where the active base stations are indicated as well as the coverage of each base station. As it is assumed that the antenna transmits the same amount of power in each direction, the coverage area of each base station is visualized by a circle. Furthermore, the tool also returns a file with technical information about each base station (e.g., input power of the antenna, height of the antenna, power consumption of the base station, etc.) 


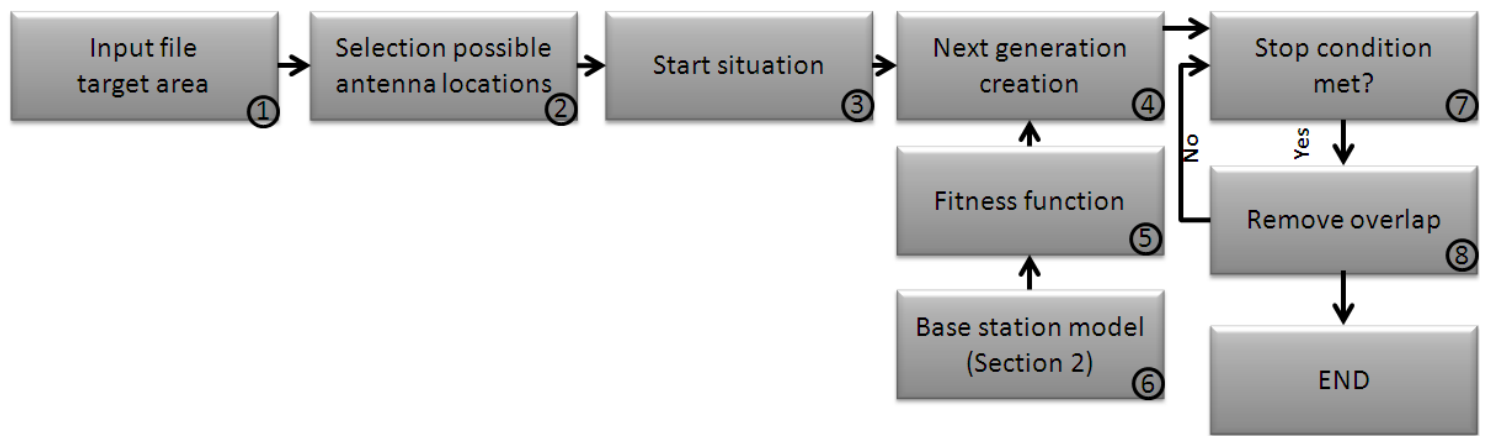

Figure 4. Flow chart of the GRAND algorithm.

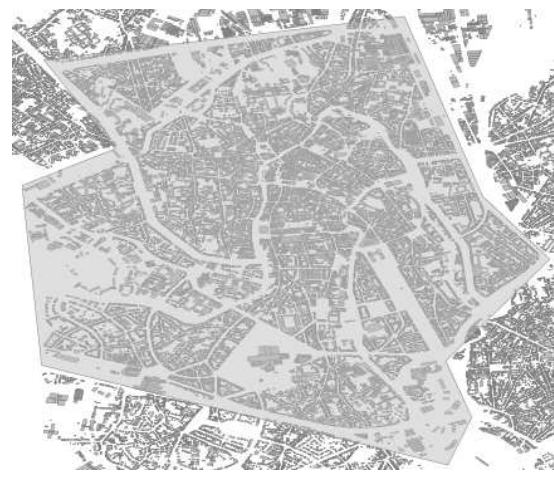

(a)

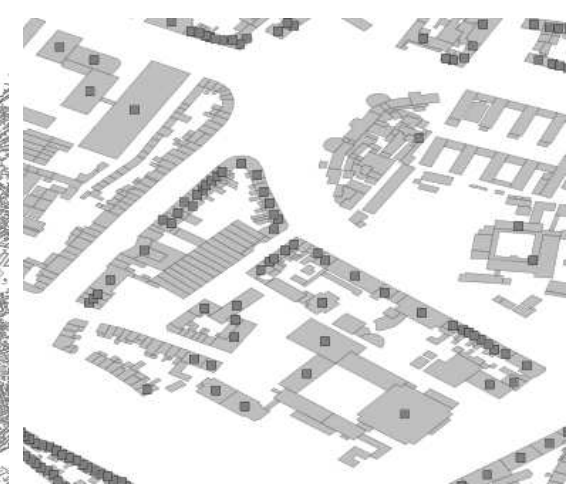

(b)

Figure 5. Shapefile of the target area for the GRAND tool (a) and a subset of possible locations for the base stations (b).

\section{RESULTS}

\subsection{Evolution of the power consumption during the day}

In this section, it is investigated how the power consumption of a macrocell and a microcell base station fluctuates during a weekday and a weekend day. Fig. 6(a) presents the power consumption of a HSPA macrocell and Fig. 6(b) the power consumption of a HSPA microcell base station as a function of the time of the day for both a weekday and a weekend.

Fig. 6 shows that the power consumption $P_{e l}$ for a microcell base station (maximum $377 \mathrm{~W}$ ) is significantly lower than for a macrocell base station (maximum $1673 \mathrm{~W}$ ). The power consumption of the macrocell base station is thus 4.4 times higher than for the microcell base station due to the higher power consumption of its air conditioning, its higher input power $P_{T x}$ of the antenna and the presence of a microwave link and multiple sectors (Section 2).

For a weekday, the lowest power consumption (i.e., $1609 \mathrm{~W}$ ) for a macrocell base station is obtained between 3 a.m. and 5 a.m. The highest power consumption (i.e., $1673 \mathrm{~W}$ ) is found between 10 a.m. and 11 a.m. For the microcell base station, the highest power consumption (i.e., $377 \mathrm{~W}$ ) is reached between 8 a.m. and 9 a.m. and the lowest power consumption (i.e., $362 \mathrm{~W}$ ) between 1 a.m. and 2 a.m. However, the course of the power consumption for a microcell base station varies more than for the macrocell base station. This is due to the fact that when there is too much traffic on one of the neighbouring macrocell base stations some of the traffic is diverted to the microcell base station. In general, the fluctuations in power consumption are limited for the microcell base station compared to the macrocell base station (Section 2.3.2).

\subsection{Comparison of the energy efficiency between macrocell and microcell base stations}

The energy efficiency of a macrocell and a microcell base station is here investigated for the technologies considered and for different bit rates. The suburban scenario of Table $\mathrm{V}$ is considered. To make a fair comparison between the macrocell and the microcell base station, the power consumption accumulated over one week for both base stations is considered. $P_{e l}$ in eq. (1) will thus correspond with the total power consumption for one week of the macrocell and the microcell base station, respectively. 


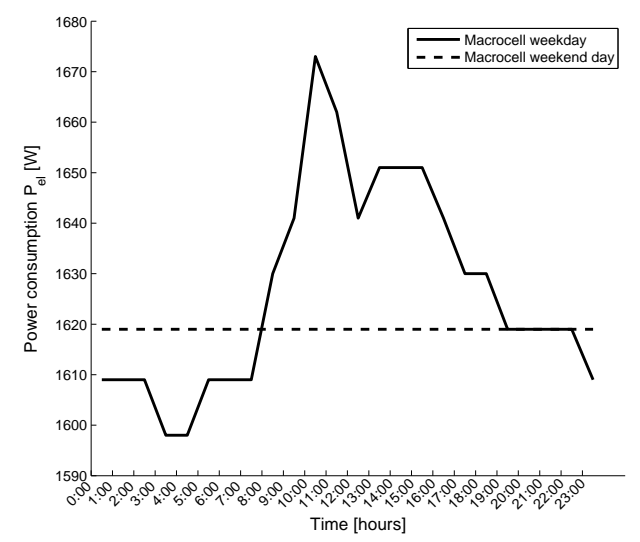

(a)

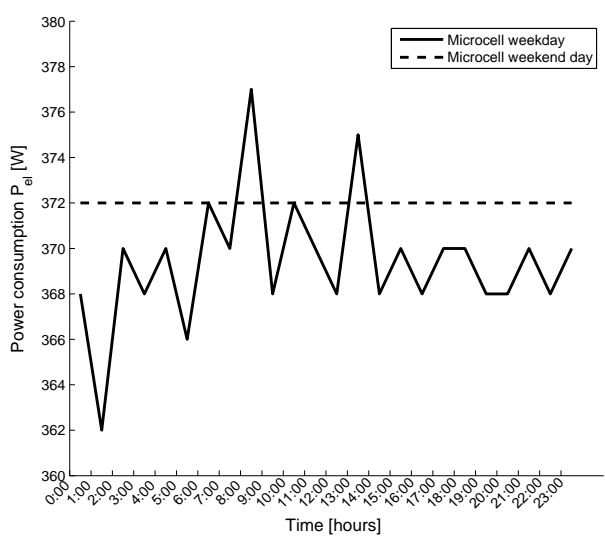

(b)

Figure 6. Evolution of the power consumption during a weekday and the weekend for a HSPA macrocell (a) and microcell (b) base station.

Fig. 7 presents the power consumption $P C_{\text {area }}$ per covered area as a function of the bit rate for both the macrocell and the microcell base station in a $5 \mathrm{MHz}$ channel.

Based on our assumptions, Fig. 7 shows that the macrocell base station is more energy-efficient (i.e., a lower $P C_{\text {area }}$ ) than the microcell base station despite its higher power consumption (Section 4.1). $P C_{\text {area }}$ is about 4 to 18 times lower for a macrocell base station than for a microcell base station (for e.g., $0.27 \mathrm{mWh} / \mathrm{m}^{2}$ versus $1.52 \mathrm{mWh} / \mathrm{m}^{2}$ for mobile WiMAX and $3.8 \mathrm{Mbps}$ ) due to the higher range obtained by the macrocell base station. The range for the macrocell base station is 4 to 8 times higher than for a microcell base station depending on the technology considered due to its higher input power $P_{T x}$, its higher antenna gain, and its higher antenna height (Table IV).

For the microcell base station, mobile WiMAX is the most energy efficient technology for bit rates higher than $3.8 \mathrm{Mbps}\left(1.91 \mathrm{mWh} / \mathrm{m}^{2}\right.$ for about $5.5 \mathrm{Mbps}$ versus $3.96 \mathrm{mWh} / \mathrm{m}^{2}$ for LTE and $6.39 \mathrm{mWh} / \mathrm{m}^{2}$ for HSPA). Mobile WiMAX performs better due to its higher antenna gain for both the base station and the mobile station (Table IV). In general and for the case considered here, HSPA is less energy efficient (higher value for $P C_{\text {area }}$ ) than mobile WiMAX and LTE due to its lower effective input power of the antenna $P_{T x}^{T C H} . P_{T x}^{T C H}$ is the power reserved by the base station for the traffic channels and is lower for HSPA because it uses WCDMA (Wideband Code Division Multiple Access) while mobile WiMAX and LTE both use SOFDMA (Scalable Orthogonal Frequency Division Multiple Access) [5].

LTE is the most energy-efficient for bit rates between $2.8 \mathrm{Mbps}$ and $3.8 \mathrm{Mbps}\left(P C_{\text {area }}\right.$ is $1.30 \mathrm{mWh} / \mathrm{m}^{2}$ for about $2.5 \mathrm{Mbps}$ versus $3.28 \mathrm{mWh} / \mathrm{m}^{2}$ for HSPA). Bit rates below $2.8 \mathrm{Mbps}$ are only supported by HSPA $\left(P C_{\text {area }}\right.$ is
$2.43 \mathrm{mWh} / \mathrm{m}^{2}$ for $1.3 \mathrm{Mbps}$ ) and not by mobile WiMAX or LTE.

For the macrocell base station, mobile WiMAX is the most energy-efficient for bit rates higher than $11.5 \mathrm{Mbps}$ (versus 3.8 Mbps for a microcell base station) due to its lower receiver SNR resulting in a higher range. For bit rates between 2.8 Mbps and 11.5 Mbps LTE is the most energy-efficient which is also due to its lower receiver SNR for this range of bit rates.

\subsection{Application: prediction of the power consumption of a wireless access network in Ghent}

In this section, it is investigated how much electrical power is needed to cover a part of the city of Ghent, Belgium. The target area is shown in Fig. 5(a) and has a surface of $13.3 \mathrm{~km}^{2}$. A coverage requirement of $90 \%$ is assumed. For each technology considered, a new network is deployed, once with only macrocell base stations and once with both macrocell and microcell base stations. The set of possible locations for the base stations are all the buildings in the target area with a height equal to or higher than $10 \mathrm{~m}$ which results in 13,437 possible locations. Some of these locations are shown in Fig. 5(b). To make a fair comparison between the different technologies, a bit rate of (approximately) $5 \mathrm{Mbps}$ is assumed in a $5 \mathrm{MHz}$ channel. This corresponds with the 2/3 QPSK, the 3/4 QPSK and the 1/2 16-QAM modulation for mobile WiMAX, LTE, and HSPA, respectively. Furthermore, the algorithm will stop when 1000 generations are generated or when the simulation lasts longer than 1 hour.

Fig. 8 gives a visual overview of the energy-efficient network with only macrocell (a) and both macrocell and microcell base stations (b) for mobile WiMAX resulting from the GRAND tool. Numerical results for all 


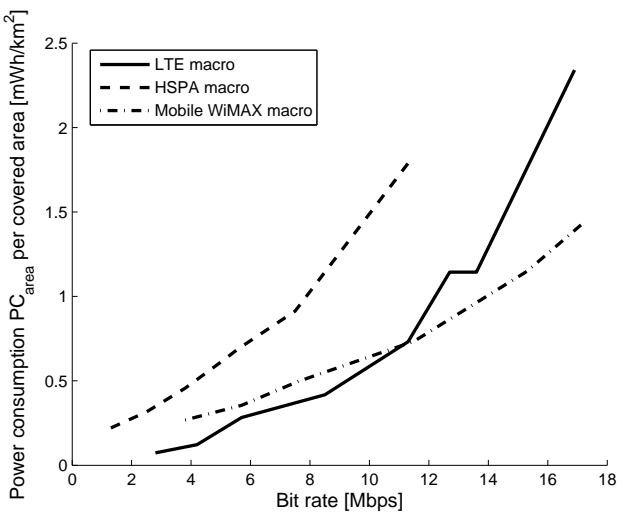

(a)

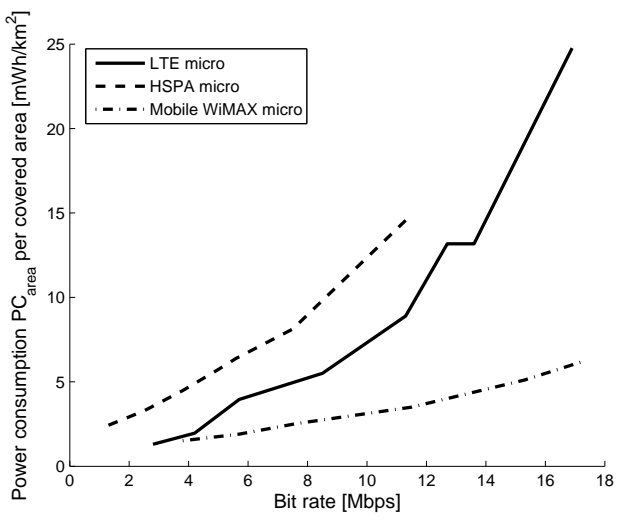

(b)

Figure 7. Comparison of the power consumption $P C_{\text {area }}$ per covered area of a macrocell (a) and microcell (b) base station in a 5 $\mathrm{MHz}$ channel for different technologies.

considered technologies are summarised in Table VI. Table VI shows that a higher energy efficiency (lower $\left.P C_{\text {area }}\right)$ is obtained when microcell base stations are introduced due to the lower total power consumption for the same coverage. The lowest total power consumption for combined macrocell and microcell base stations is found for LTE (81.9 $\mathrm{kW})$, followed by mobile WiMAX $(83.8 \mathrm{~kW})$, and HSPA $(178.0 \mathrm{~kW})$. For HSPA, the energy efficiency gain is very limited as the coverage of the network with both macrocell and microcell base stations is much lower than when only macrocell base stations are used $(94.9 \%$ versus $97.7 \%)$.

Fig. 9 shows the time behaviour of the power consumption by illustrating the evolution of $P C_{\text {area }}$ during a week day for the network with only macrocell base stations and for the network with both the macrocell and the microcell base stations. $P C_{\text {area }}$ of each network follows the curve of the macrocell base station's power consumption (as given in Fig. 6(a)). For the networks with both macrocell and microcell base stations, this is due to the fact that there is a much larger amount of macrocell base stations present in the network compared to the microcell base stations. Furthermore, the power consumption of the microcell base stations varies less compared to that of a macrocell base station as mentioned before.

\section{RELATED WORK}

As increasingly more attention is drawn to the power consumption in wireless access networks, the topic starts to appear in literature $[19,25,16,26]$. In [25], a model is proposed where the power consumption is characterized by three parameters: the transmission power, the efficiency of the transmission chain, and a parameter that contains all the other power needed. $[16,26]$ both present a model where the power consumption is a function of the load. In [19], the authors propose a power consumption model for both macro and micro sites. Our study differs from these studies in several aspects. Firstly, each component of the base station is modelled individual, while the other studies combine different components in one parameter which makes it difficult to investigate the influence of the different components on the total power consumption, as well as possible dependencies between the components. Secondly, our study compares the energy efficiencies of different technologies, whereas the other studies focus only on one wireless technology. Finally, our work is based on real measurements taken from an operation network which also gives a good indication of the accuracy of the predicted values.

[17] also proposes a power consumption model as a function of the traffic load in an operational 3G UMTS network, while our study combines measurements on a UMTS microcell base station and HSPA macrocell base station. However, this study agrees with our conclusion that traffic (or load) variations are not followed by similar variations in power consumption. This conclusion is also confirmed by $[16,26]$.

Finally, in [27], a similar deployment tool is discussed which designs single frequency terrestrial DVB (Digital Video Broadcasting) networks while minimizing the carbon emissions of the network. However, GRAND develops networks for a broader range of wireless access technologies. Furthermore, GRAND allows also to develop hybrid macrocell and microcell base stations.

\section{CONCLUSION}

In this paper, a power consumption model is proposed for both macrocell and microcell base stations and validated by temporal measurements. The evolution of the power 


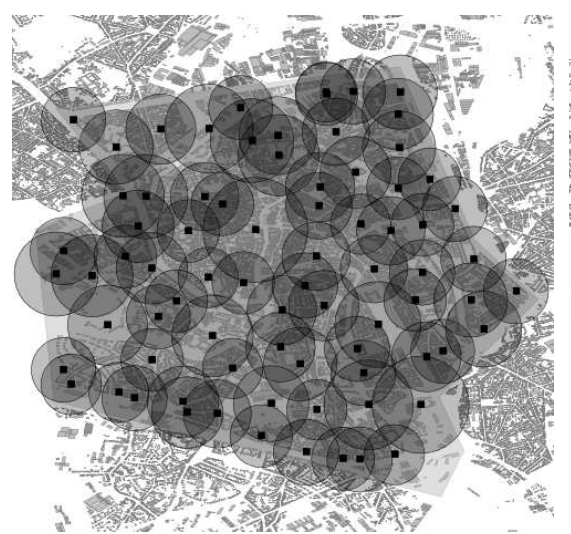

(a)

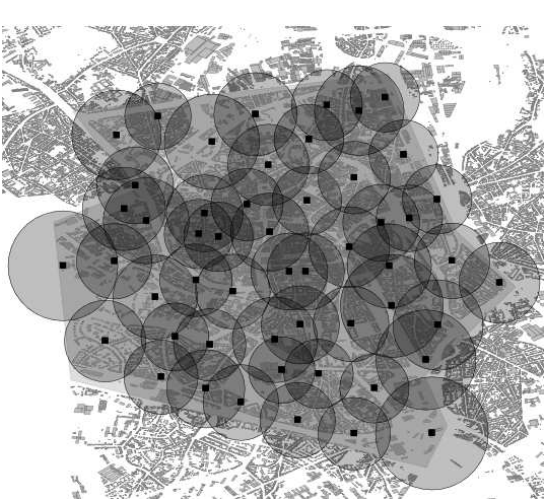

(b)

Figure 8. Energy-efficient network with only macrocell base stations (a) and with both macrocell and microcell base stations (b) for mobile WiMAX resulting from the GRAND tool.

\begin{tabular}{|l|c|c||c|c||c|c|}
\hline Parameter & $\begin{array}{c}\text { mobile WiMAX } \\
\text { macro }\end{array}$ & $\begin{array}{c}\text { mobile WiMAX } \\
\text { macro + micro }\end{array}$ & $\begin{array}{c}\text { LTE } \\
\text { macro }\end{array}$ & $\begin{array}{c}\text { LTE } \\
\text { macro + micro }\end{array}$ & $\begin{array}{c}\text { HSPA } \\
\text { macro }\end{array}$ & $\begin{array}{c}\text { HSPA } \\
\text { macro + micro }\end{array}$ \\
\hline Number of macrocells [-] & 78 & 66 & 52 & 50 & 114 & 109 \\
\hline Number of microcells [-] & - & 4 & - & 2 & - & 3 \\
\hline $\begin{array}{l}\text { Average total } \\
\text { power consumption }[\mathrm{kW}]\end{array}$ & 97.2 & 83.8 & 83.2 & 81.9 & 184.8 & 178.0 \\
\hline Coverage $[\%]$ & 97.6 & 97.4 & 99.3 & 99.1 & 97.7 & 94.9 \\
\hline Average $P C_{\text {area }}\left[\mathrm{kW} / \mathrm{km}^{2}\right]$ & 7.5 & 6.5 & 6.3 & 6.2 & 14.2 & 14.1 \\
\hline
\end{tabular}

Table VI. Comparison between the networks with only macrocell base stations and with both macrocell and microcell base stations for the technologies considered (5 Mbps in a $5 \mathrm{MHz}$ channel).

consumption during the day is investigated by means of these measurements. Based on this model, the energy efficiency of three different wireless technologies is considered, namely mobile WiMAX, HSPA, and LTE. This model is then used in the deployment tool GRAND which allows to design an energy-efficient network for a predefined target. This tool allows us to investigate the influence of the introduction of microcell base stations in the network on the energy efficiency and the power consumption.

Based on the assumptions made, it was found that a microcell base station consumes, in general, about 4.4 times less than a macrocell base station. However, a macrocell base station is more energy-efficient than a microcell base station as a higher coverage is obtained with a macrocell base station. Furthermore, the measurements agree excellently with the proposed models.

A higher energy efficiency is obtained when microcell base stations are introduced in the network because a lower total power consumption is obtained (for all technologies) for the same coverage. It is thus concluded that although a single microcell base station has a lower energy efficiency than a macrocell base station, it is useful to introduce microcell base stations in the network.
In the future, both cell zooming and sleep modes should be added to both the model and the GRAND tool. Cell zooming is a technique whereby the cell size is adjusted according to traffic load, user requirements, and channel conditions. When sleep modes are introduced in the network, base stations can be switched off during periods of low or no traffic. For both cell zooming and sleep modes, a traffic model needs to be composed. Furthermore, we will also extend the GRAND tool to make optimizations towards capacity possible.

\section{ACKNOWLEDGEMENT}

The work described in this paper was carried out with the support of the IBBT-project GreenICT. W. Joseph is a Post-Doctoral Fellow of the FWO-V (Research Foundation Flanders).

\section{REFERENCES}

1. G. Koutitas, P. Demestichas, A Review of Energy Efficiency in Telecommunication Networks, 17th 


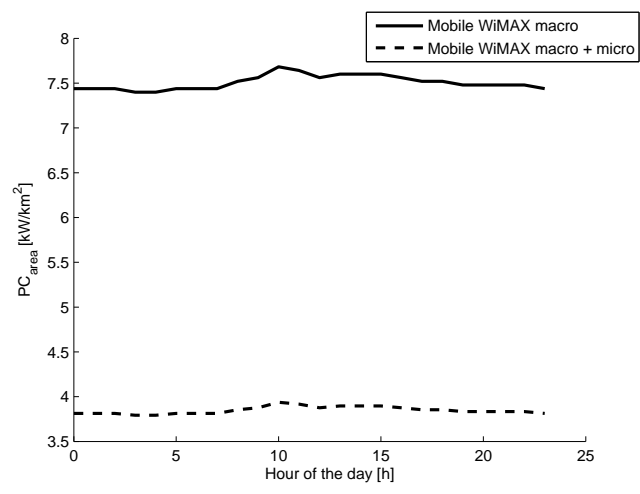

(a)

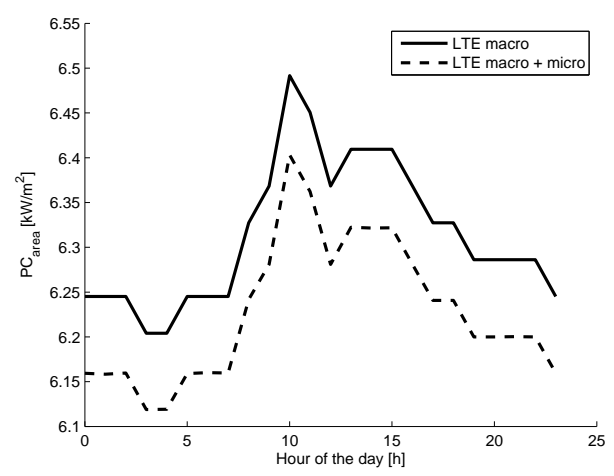

(b)

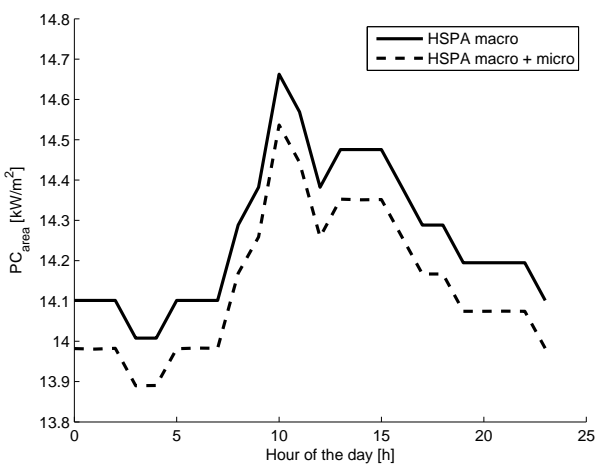

(c)

Figure 9. Evolution of $P C_{a r e a}$ of the networks as a function of the hour of the day with only macrocell base stations and with both macrocell and microcell base stations for mobile WiMAX (a), LTE (b), and HSPA (c).

Telecommunications forum TELFOR 2009, Serbia, Belgrade, November 24-26, 2009.

2. Part 16: Air Interface for Fixed and Mobile Broadband Wireless Access Systems: Amendment 2: Physical and Medium Access Control Layers for Combined Fixed and Mobile Operation in Licensed Bands and Corrigendum 1, IEEE Computer Society and the IEEE Microwave Theory and Techniques Society, February 2006.

3. LTE: 3rd Generation Partnership Project: Technical Specification Group Radio Access Network: Evolved Universal Terrestrial Radio Access (E-UTRA): User equipment (UE) radio transmission and reception (TS 36.101 v9.1.0 Release 9), 3GPP, September 2009.

4. 3rd Generation Partnership Project: Technical Specification Group Radio Access Network: Physical layer aspects of UTRA High Speed Downlink Packet Access (Release 4), TR 25.848 v4.0.0, 3GPP, March 2001.

5. M. Deruyck, E. Tanghe, W. Joseph, L. Martens, Modelling and optimization of power consumption in wireless access networks, Elsevier Computer Communications, doi:10.1016/j.comcom.2011.03.008, accepted 15 March 2011.

6. L. M. Correia, D. Zeller, O. Blume, D. Ferling, Y. Jading, I. Gódor, G. Auer, L. Van der Perre, Challenges and Enabling Technologies for Energy Aware Mobile Radio Networks, IEEE Communications Magazine, Vol. 48, Issue 11, November 2010, pp. 66-72.

7. Pfannenberg, http://www.pfannenbergusa.com/catalog/ catalog-downloads/2010_Catalog.pdf, 2010.

8. F. H. Raab, P. Asbeck, S. Cripps, P. B. Kenington, Z. B. Popovic, N. Pothecary, J. F. Sevic, N. O. Sokal, $R F$ and Microwave Power Amplifier and Transmitter Technologies - Part 1, High Frequency Electronics, May 2003, pp. 22-36.

9. Ophir RF, model 5303009, 5303025, 5303075, 5303018A, 5303023, 2010.

10. Power-One S series, 2010.

11. Daikin FUQ125BW13/R2Q125D7413, FHQ35BW1B, 2010.

12. Allgon Microwave - AMR Transcend PLUS, 2010.

13. Ceragon Networks - FibeAIR 1500P Family, 2010. 
14. Trangobroadbandnetworks - TrangoLINK - Giga, 2010.

15. W. Joseph, L. Verloock, E. Tanghe, L. Martens, In-situ measurement procedures for temporal $R F$ electromagnetic field exposure of the general public, Health Phys, Vol. 96, No. 5, May 2009, pp. 529-542.

16. G. Micallef, P. Mogensen, H.-O. Scheck, Cell Size Breathing and Possibilities to Introduce Cell Sleep Mode, European Wireless Conference 2010, Lucca, Italy, April 2010, pp. 111-115.

17. C. Peng, S.-B. Lee, S. Lu, H. Luo, H. Li, TrafficDriven Power Saving in Operational $3 G$ Cellular Networks, 17th annual international conference on Mobile Computing and networking (MobiCom), 2011, doi:10.1145/2030613.2030628.

18. S. Saunders, Antennas and Propagation of Wireless Communication Systems, Wiley, 1999.

19. F. Richter, A. J. Fehske, G. P. Fettweis, Energy Efficiency Aspects of Base Station Deployment Strategies for Cellular Networks, IEEE 70th Vehicular Technology Conference Fall (VTC 2009-Fall), Anchorage, Alaska, September 2009, pp. 1-5.

20. M. Deruyck, W. Vereecken, E. Tanghe, W. Joseph, M. Pickavet, L. Martens, P. Demeester, Power consumption in wireless access networks, European Wireless conferece, April 2010, Lucca, Italy, pp. 924931.

21. S. Bhaumik, G. Narlikar, S. Chattopadhyay, S. Kanugovi, Breathe to Stay Cool: Adjusting Cell Sizes to Reduce Energy Consumption, First ACM SIGCOMM Workshop on Green Networking, 2010, New Delhi, India, pp. 41-46.

22. V. Erceg, L. Greenstein, S. Tjandra, S. Parkoff, A. Gupta, B. Kulic, A. Julius, R. Bianchi, An Empirically Based Path Loss Model for Wireless Channels in Suburban Environments, IEEE Journal on Selected Areas in Communications, vol. 7, no. 7, July 1999, pp. 1205-1211.

23. Commission of the European Communications and COST Telecommunications, COST 231 Final report, Digital Mobile Radio: COST 231 View On the Evolution towards 3rd Generation Systems, Brussels, Belgium, 1999.

24. ESRI, ESRI Shapefile Technical Description - White paper, 1998.

25. M. Jada, J. Hämäläien, R. Jäntti, M. M. A. Hossain, Power Efficiency Model for Mobile Access Network, the 21st Annual IEEE International Symposium on Personal, Indoor and Mobile Radio Communications: Workshop on Wireless Green (PIMRC 2010, WGREEN), Istanbul, Turkey, September 2010, pp. 316321.

26. G. Auer, V. Giannini, C. Desset, I. Gódor, P. Skillermark, M. Olsson, M. A. Imran, D. Sabella, M. J. Gonzalez, O. Blume, A. Fehske, How Much Energy is Needed to Run A Wireless Network, IEEE Wireless Communications, Vol. 18, No. 5, October
2011, pp. 40-49.

27. G. Koutitas, Low Carbon Network Planning, European Wireless Conference, Lucca, Italy, April 2010, pp. 411-417.

\section{AUTHORS' BIOGRAPHIES}

Margot Deruyck was born in Kortrijk, Belgium on July 14, 1985. She received her M. Sc. degree in computer science engineering from Ghent University in July 2009. Since September 2009 she has been a research assistant in the Wireless and Cable (WiCa) research group at INTEC UGent/IBBT. Her scientic work is focused on green wireless access networks with minimal power consumption and minimal exposure of humans.

Wout Joseph received his M. Sc. degree in electrical engineering from Ghent University (Belgium) in July 2000. From September 2000 to March 2005, he was a research assistant at the Department of Information Technology (INTEC) of the same university. During this period, his scientific work was focused on electromagnetic exposure assessment. His research work dealt with measuring and modelling of electromagnetic fields around base stations for mobile communications related to the health effects of the exposure to electromagnetic radiation. This work led to a $\mathrm{Ph}$. D. degree in March 2005. Since April 2005, he is postdoctoral researcher for IBBT-Ugent/INTEC (Interdisciplinary institute for BroadBand Technology). Since October 2007, he is a Post-Doctoral Fellow of the FWO-V (Research Foundation Flanders). Since October 2009 he is professor in the domain of Experimental Characterization of wireless communication systems. His professional interests are electromagnetic field exposure assessment, propagation for wireless communication systems, antennas and calibration. Furthermore, he specializes in wireless performance analysis and Quality of Experience.

Luc Martens was born in Ghent, Belgium on May 14, 1963. He received the MSc degree in electrical engineering and a $\mathrm{PhD}$ degree in development of a multichannel hyperthermia system: electromagnetic modeling of applicators, generator design, and estimation algorithms for thermometry from Ghent University (Belgium), in July 1986 and December 1990, respectively. From September 1986 to December 1990, he was a research assistant at the Department of Information Technology (INTEC), Ghent University. Since January 1991, he has been a member of the permanent staff of the Interuniversity MicroElectronics Center (IMEC), Ghent and is responsible for the research on experimental characterization of the physical layer of telecommunication systems at INTEC. Since April 1993, he has been a professor of electrical applications of electromagnetism at Ghent University. 